\title{
Research of Enterprise Environmental Cost Control based on Ecological Economics
}

\author{
Yingrong Zheng ${ }^{1}$, Hao Dong ${ }^{1}$ \\ ${ }^{1}$ Shandong Vocational College of Science and Technology, Weifang, Shandong, 261053
}

Keywords: Enterprise Environment, Cost Control, Ecological Economics

\begin{abstract}
Vigorously developing circular economy and building a recycling-oriented society should start from building a recycling-oriented enterprise. From the perspective of cost management, building a recycling-oriented enterprise should start from establishing the optimal cost management objectives of economic, environmental and social benefits, introducing the concept of product life cycle cost management, and expanding the producer responsibility. As the principle of cost management, the " $3 \mathrm{R}$ " principle pays attention to the environmental cost management of the product life cycle, shifts the focus of cost management to cost prevention, and establishes a three-dimensional control mechanism that integrates the system and the environment.
\end{abstract}

\section{Introduction}

Human environmental problems can be traced back to the distant past, but in different historical periods, the types of environmental problems are different. At a stage when food depends on the gift of nature, humans are experiencing problems of excessive fishing and hunting and the loss of balance of the biomes. In the agricultural society, human beings are experiencing the problem of excessive ecological damage caused by excessive reclamation and overgrazing. In the former industrial society, human beings encountered environmental problems with a sharp decline in non-renewable resources and increasing pollution. In post-industrial societies, humans are likely to encounter environmental problems caused by excessive radiation. American biologist E.Q. Wilson pointed out: "The worst thing that can happen is not energy exhaustion, economic collapse, limited nuclear war or conquest by a totalitarian government. For us, these Despite the terrible disaster, disasters can be remedied after generations. However, the loss of genetic material and species diversity due to the destruction of natural habitats will take millions of years to correct. This is us. The children and grandchildren can't forgive our stupid things.

\section{Contemporary environmental actions}

After all, the environmental crisis must be resolved by action. As people's awareness of environmental concerns gradually sublimates into awareness of environmental participation, the social influence of shouting will undoubtedly show a declining trend. This is the main reason why in May 1992, when Meadows and others wrote the "Excessive Growth" in sharp words, there was basically no main cause of social concern. Needless to say, the common shortcoming of these studies is to underestimate the role of technological innovation. Even if we do not consider the practical possibility of reducing economic growth that is widely accepted by society, if there is no technological innovation to replace scarce resources, the resources that have been included in the scope of use will be less, even if the economic growth rate is very low, one day will not last. If there is no technological innovation to reduce or even eliminate production waste, the accumulation of "three wastes" will increase. Even if the economic growth rate is very low, it will one day be greater than the ecological irreversible threshold. Therefore, the key to sustainable development is to replace the relatively scarce resources that have been included in the scope of utilization with relatively rich resources that have not been included in the scope of utilization, and to continuously carry out technological innovations aimed at expanding the range of resources available for utilization. For example, through technological innovation, turning silicon into a usable resource 
has brought earth-shaking changes to the world. The second is to improve the way resources are used and improve the level of resource utilization. For example, forests have so far experienced a stage of fertilizer utilization based on their individual components, a stage of fuel utilization based on their energy, a stage of material utilization based on their physical form, and a stage of fuel utilization based on their chemical composition. It is currently entering an environmental utilization phase based on its overall functionality. In the course of history, human beings rely on technological innovation to change the structure of resource utilization and the efficiency of resource utilization, and continue to push civilization to new milestones. If this ability of human beings has a tendency to accelerate growth, then there is reason to be confident in your future.

In the process of social development, human beings have indeed encountered various problems, and even many ecological disasters have occurred, including the local destruction of civilizations. But on the whole, human beings can rely on their own discovery, creation and corrective ability to maintain ecology and environment. Persistence. With this ability, human beings continue to replace production technologies with poor resource utilization and low sustainability with production technologies with better resource utilization and stronger sustainability, which have lasted for 1 million years on Earth. It is getting better and better, and in some historical places that have been ruined by devastating blows to create new prosperity. Without this ability, humanity cannot continue to this day.

\section{From the perspective of cost management, the construction of a recycling-oriented enterprise}

To develop a circular economy, countries, enterprises, consumers and other stakeholders must change their concepts and make reforms in related aspects such as systems, policies, technologies, and management. To build a recycling-oriented enterprise from the perspective of cost management, enterprises should improve and innovate existing cost control technologies, continuously reduce resource consumption, introduce the concept of product life cycle cost, broaden the content and scope of cost management, and shift the focus of cost management. From "after-the-fact cost control" to "pre-existing cost prevention"; at the same time, the government should actively regulate and guide and promote the construction of recycling-oriented enterprises and society.

The circular economy emphasizes the unity of economic, environmental and social benefits. To emphasize economic benefits, it is necessary to obtain as much output as possible under the circumstances of investment, or to save as much as possible under the established conditions. Environmental benefits refer to changes in the quality of the environment caused by human activities. The impact of human activities on the environment generally takes a while to appear, so that environmental benefits are slow, such as pollutants emitted by factories in the water for a period of time before water pollution occurs. Social benefits refer to the social effects of human activities and an evaluation of the results of economic activities from a social perspective. From the perspective of environmental protection, social benefits are characterized by an increase in the physical fitness of the residents, a reduction in the incidence rate and an increase in the lifespan. In short, the improvement in the quality of life of the residents.

Traditional enterprise cost management over-emphasizes economic benefits, while paying insufficient attention to environmental and social benefits. Because for enterprises, enterprises directly benefit from economic benefits, but indirectly benefit from environmental and social benefits; in time sequence, economic benefits appear to be significantly faster than environmental and social benefits. Therefore, in the traditional ideological understanding, people are accustomed to operating in the circle of the economic system, often out of economic activities and environmental protection. However, with the intensification of the global environment, resources and energy issues, people are increasingly aware that social reproduction and environmental systems are unified. Social reproduction connects the economic system and the environmental system as a whole by acquiring resources and discharging waste into the environment. Therefore, the unification of economic benefits and environmental benefits is required. The poor ecological benefits generated in the production process of the enterprise can lead to the reduction of the overall 
economic benefits, and the connotation of economic benefits itself includes the improvement of environmental benefits. Increasing economic benefits include the increase in the supply of natural resources, as well as the rational development and utilization of natural resource production factors and the comprehensive utilization of waste, which are also conducive to the improvement of environmental benefits. In short, economic and environmental benefits are interdependent and mutually restrictive. The latter is the natural foundation and material source of the former. The former is the economic expression of the latter, and the two are dialectical and unified. Emphasis on economic and environmental benefits is aimed at social benefits, so that all aspects of society can be developed and improved, so that people have a better social living environment and improve the quality of life. Therefore, the reasonable choice of the cost management objectives of the recycling-oriented enterprise is to optimize the economic, environmental and social benefits.

\section{Update of enterprise cost management principles}

The principle of extended producer responsibility (EPR) has emerged in Europe since the 1990s, and has achieved great results in resource management and waste disposal. This principle extends traditional producer responsibility to the entire life cycle of a product, including the processing of the product after its lifetime. Producers are not only responsible for the performance of the product, but also bear full responsibility for the environmental impact of the product from design, production to disposal. The principle of expanding producer responsibility has become the basic principle that developed countries have followed in implementing waste product management and pollution control in the past decade. Xinhuanet reported on April 18, 2006 that during the "Eleventh Five-Year Plan" period, the central government will promote the reform of the system of paid use of the environment, and urge enterprises to incorporate environmental costs into the production costs or service prices of enterprises, and internalize the external costs of environmental pollution. Corporate socialization. It can be seen that "expanding producer responsibility" will also become the basic principle for establishing a circular economy institutional framework in China. The principle of expanding producer responsibility emphasizes the leading role of firms as producers in cost management. Because the enterprise is the most controllable role in the product life cycle. Only companies that are producers can determine the improvement of product design, and are most capable of exploiting the maximum use value of discarded products, and are also the most direct users of renewable resources. Therefore, enterprises should actively manage environmental costs and social costs on the basis of traditional cost management, minimizing waste and recycling renewable resources.

To build a recycling-oriented enterprise, the technological innovation and management activities of the enterprise must follow the "3R" operating principle of circular economy. From the perspective of generalized product life cycle cost management, first of all, in product design, we must rationally design products according to the "3R" principle of circular economy, and pay attention to saving resources and reducing pollution from the source. Enterprises should adjust the product design or select the product according to the prediction of the environmental protection cost of the product, such as some highly polluting products (radioactive components, pulp, etc.) or products that will produce a lot of pollution in the production process, if still traditional When the cost management is forecasted, it will ignore its considerable environmental protection cost, and will magnify the profit of the product even if it is actually a profitable product that is mistaken for profit, thus misleading the enterprise's business decision-making, resulting in the enterprise. Unnecessary loss of benefits. On the other hand, some environmentally friendly products that are easy to recycle will make more contributions to resource conservation and environmental protection. Under the circular economy framework, this contribution should also be considered in enterprise cost management, and, because of the government. Some related environmentally friendly policies, these contributions can often bring returns to enterprises, such as tax relief, financial subsidies, etc., which makes these products have certain advantages in the market, and, along with people's green environmental protection concept Popularization and attention, these environmentally friendly products will also be increasingly favored by consumers. In the production stage of the product, the 
recycling economy requires the use of resources (materials) that are recyclable, recyclable, and efficient and low-cost in production. Reduce or avoid the use of resources (materials) that may cause pollution. Rational and sustainable development and utilization of resources, while applying green technology, implementing "clean production" to control the environmental costs of the production process and final products. In the management and control of packaging costs, unnecessary packaging is removed, packaging is reduced, and recyclable packaging is used. Change the texture of packaging materials and actively promote the use of paper bags and degradable bags. Actively adopt the IS O14000 series of standards to establish an environmental labeling system for green products that meets the requirements of circular economy standards. Minimize the generation of waste and improve the comprehensive utilization rate of waste resources. It is necessary to vigorously recycle and recycle various waste resources, establish a recycling system for old-for-new, and reuse resources through trade-in and reduce pollution to the ecological environment.

\section{Conclusion}

Environmental and ecological economics research has effectively enhanced human environmental crisis awareness and environmental participation awareness, and has effectively enhanced environmental policy research and scientific and technological research, especially its positive role in adjusting human capital allocation. The early arrival of the era of science and life sciences, and thus the sustainable development of human society, plays an extremely important role.

\section{References}

[1] Ren Jizhou. Grassland Science Framework Structure and Teaching Practice [J]. Higher Education of Science, 2010, 90(4): 1-7.

[2] Li Dongsheng. Necessity and possibility of reform of practical teaching links in agriculture and forestry economic management specialty [J]. Higher Agricultural Education, 2001, 122(8): 64-65.

[3] Zheng Yu. Preliminary study on the reform of the teaching and management of the economic and management specialty of the agricultural and forestry colleges in the university [J]. Theory and Practice, 2012, 121(11): 43-44.

[4] Liu Yupeng, Zhao Huifeng. Research on the construction of practical teaching module system for agriculture and forestry economic management specialty [J]. Journal of Hebei Agricultural University (Agriculture and Forestry Education Edition), 2015, 17 (1): 114-117.

[5] Wang Guangyi. Experimental teaching concept and innovation ability training [J]. Laboratory Research and Exploration, 2008, 27(8): 76-78.

[6] Nan Zhibiao, Fu Hua, Long Ruijun, et al. Constructing advanced grassland scientific talent training system under the guidance of grassland scientific theory [J]. Higher Education of Science, 2009, 84(2): 124-127. 